\title{
Simulation of a parallel mechanical elbow with 3 DOF
}

\author{
J. R. Mendoza-Vázquez*1 ${ }^{1}$, E. Tlelo-Cuautle ${ }^{2}$, J.L. Vázquez-Gonzalez ${ }^{3}$, A. Z. Escudero-Uribe ${ }^{4}$ \\ 1,2,4 Instituto Nacional de Astrofísica, Óptica y Electrónica, Puebla, México \\ ${ }^{3}$ Universidad de las Américas Puebla (UDLA-P) \\ *jrmendoza@inaoep.mx
}

\begin{abstract}
The kinematics simulation and modeling of a mechanical elbow of 3 degrees of freedom, is introduced by highlighting the main features of the mechanism related to the design criteria. The mechanical elbow is used as a transhumeral prosthetic part, and it has been built as a parallel topology consisting of electric linear actuators and universal joints. The parallel mechanism has 4 legs. 3 are electric linear actuators, and the fourth leg provides mechanical support for the whole structure and holds a DC Motor that performs the action of gripping objects. Furthermore, this paper shows the inverse kinematics for the elbow by geometric methods, and the MatLab-simulation results show the workspace of the movement and the ability of the mechanical elbow to replicate the movements of a biological one.
\end{abstract}

Keywords: Kinematics, Modeling, Simulation, Robot kinematics.

\section{RESUMEN}

El propósito de este documento es mostrar el modelado y simulación de un codo mecánico de 3 grados de libertad empleado como prótesis de codo transhumeral. El mecanismo paralelo tiene 4 piernas de las cuales 3 son actuadores eléctricos lineales y la cuarta pierna proporciona soporte mecánico para toda la estructura y aloja un motor que realiza la prensión de objetos. En el trabajo se resumen las principales características del mecanismo acorde con los criterios de diseño empleados. Se desarrolla la cinemática inversa para el codo por métodos geométricos y los resultados son usados con propósitos de simulación para mostrar el espacio de trabajo y su capacidad de movimiento para replicar los movimientos de un codo biológico. Las simulaciones son desarrolladas bajo el ambiente de MatLAB.

Palabras clave: cinemática, simulación, modelado, cinemática de robot.

\section{Introduction}

Current research in prosthetics has been focused on the development of prosthetic hands and prosthetic legs [1]. However, the research and development of elbows is very poor and current research has only been focused on prosthetic elbows with one degree of freedom (DOF). In the same manner, both mechanical and myoelectric prosthetic elbows [2] are serial and with a single DOF, such as Utah Arm [3], and the Edinburgh Arm [4]. An improved development is a serial mechanism with 3 DOF [5], but with the disadvantage that it is not suitable for high weights and its electronic devices are not portable so it cannot be used in prosthetic elbows. Similar developments with pneumatic muscles present this problem [6]. In contrast, a complete and functional prosthetic elbow must have 3 motorized axes in order to provide 3 DOF [7][8], namely: flexion-extension, pronation-supination and humeral rotation, as shown in Fig. 1. These movements can be defined with major axes according to [9][10], and this capacity lets us evaluate the movements required for a prosthetic elbow, which should perform the movements of a biological one.

In [11]-[12], a new motorized design of a prosthetic elbow performing flexion-extension, pronation-supination, and humeral rotation, with the characteristic of having electrical drives actuators in a parallel topology is introduced, as shown in Fig. 2. Its main advantage is that it provides an improved workspace higher than typical parallel robots, due to the mechanical 
configuration and universal joints. Most importantly it is that the link of the mechanical elbow supports high loads and allows a workspace fitness for a prosthetic hand with 3 DOF. Henceforth, in this paper a general description on the modeling and simulation of the prosthesis and its ability to emulate human elbow movements is introduced.

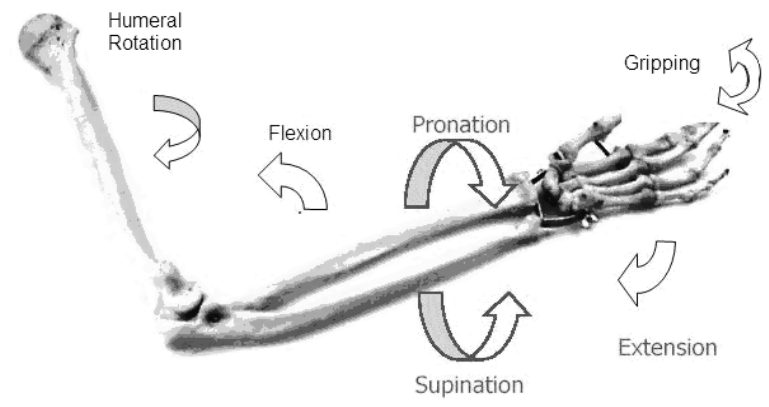

Figure 1. Movements of a human elbow: flexionextension, pronation- supination, and humeral rotation.

\section{Elbow prosthesis mechanism}

\subsection{Design basics}

There are different types of actuators [13]-[14], but we have found that the best electrical actuators are those that have the following characteristics: small size, low weight, low power consumption, high torque, the best power/volume ratio silent operation, minimal heat generation, fast response and simple control. The important part in the selection of an actuator is related to giving the prosthesis enough space to contain the electrical and electronic components. In this work, we used a DC brushless motor to have better power/volume and power/weight ratio than with brushed or induction motors. The mechanical design of the elbow was developed in Solid Edge, exploiting its ability to make kinematic and dynamic simulation
For instance, the basic concepts involved in the modeling and simulation of the parallel mechanical elbow of 3 DOF are modularity, self-contained and anthropometric relations.

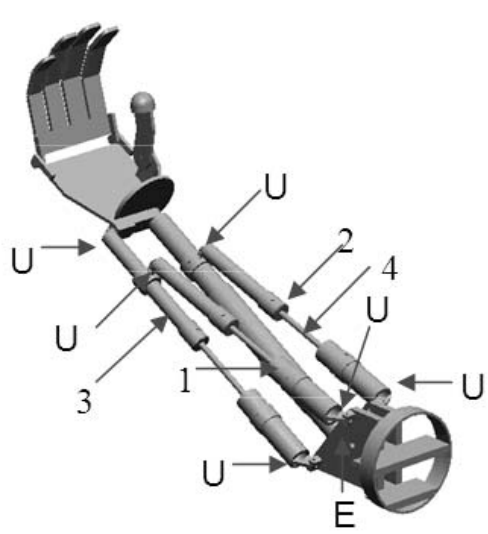

Figure 2. Elements of the mechanism/prosthesis proposed in [13]-[14]. It is a parallel topology with 3 linear actuators $(1,2,3)$, and a fourth leg which supports the mechanical structure.

\subsection{Overview of the mechanism}

As shown in Fig. 2, the mechanism has four legs (links), one is fixed and enables the mechanism to have structural rigidity, and it contains the servomotor allowing the movement of the hand gripping. Equally important, the other three legs are in parallel configuration consisting of linear actuators.

The elbow has a mechanical structure less than 1 $\mathrm{Kg}$ of weight. Its dimensions are approximately 30 $\mathrm{cm}$ long, $8 \mathrm{~cm}$ in diameter. The placement of the actuators is based on the biological structure of the upper limb, where each joint is driven by at least two muscles. Therefore, each movement is performed by activating at least two actuators in parallel. Basically, the parallel configuration of actuators allows the adding of their forces. This configuration allows the system to perform a 
major number of forces on the same point, and it reflects the best employment of the components.

As a result, this system provides better characteristics of strength and lightness. Robustness, which has several links that give greater stability and lightness than the ratio of load-force capacity, is much higher compared with serial prosthesis, because the structure is lighter and the force is divided between the numbers of parallel actuators.

\section{Modeling}

The construction of the kinematic model for a parallel-robot does not have the same characteristics as for a serial robot. In the majority of serial robots, the Denavit-Hartenberg methodology is applied [15], where one can obtain a direct kinematic model in a systematic manner, and it is independent of its physical configuration.

To obtain the inverse kinematic model of a parallel mechanism, the use of geometric considerations for each configuration and numerical methods for solving the system of equations is required. However, in parallel robots, the direct kinematic model is quite complex to derive, and in many cases it cannot have a single analytical solution [16]. Besides, there are pioneering studies on kinematic models such as the interval analysis [17], [18], topological synthesis [19], quadratic form [20], complex linear approximation [21], theory screws [22], kinetostatic model [23], and Lie algebra [24], among others. Furthermore, in the case of the parallel mechanical elbow described herein, we use the methods proposed in [25]-[28].

\subsection{Kinematic model}

For the kinematic modeling, it can be assumed that the mechanism behaves as a single block [29], due to the configuration of the legs. In Fig. 2, the cylinders work as follows: the movement of humeral rotation is labeled by angle $\theta$, the bending of the elbow is labeled by $\gamma$, and pronation and supination by $\beta$. The dimensions of the cylinders labeled by $\gamma$ and $\theta$ are infinity small, since their joint is spherical. These considerations are necessary because the joint is considered spherical.

According to a kind of Euler angle, the parallel mechanism has the rotation matrix described by (1). The mechanism allows the workspace shown in Fig. 3, based on the ranges of movement for a biological elbow. As can be seen, the space is semispherical and includes ranges of motion involving the operation of the electric linear actuators (parallel mechanism for the elbow).

${ }^{A} R_{B}=\left[\begin{array}{lll}u_{x} & v_{x} & w_{x} \\ u_{y} & v_{y} & w_{y} \\ u_{z} & v_{z} & w_{z}\end{array}\right]=\left[\begin{array}{ccc}c \theta c \beta-c \gamma s \theta s \beta & -c \gamma c \theta c \beta-c \theta s \beta & -s \gamma s \theta \\ c \gamma c \theta s \beta+s \theta c \beta & c \gamma c \theta c \beta-s \theta s \beta & s \gamma c \theta \\ -s \gamma s \beta & -s \gamma c \beta & c \gamma\end{array}\right]$

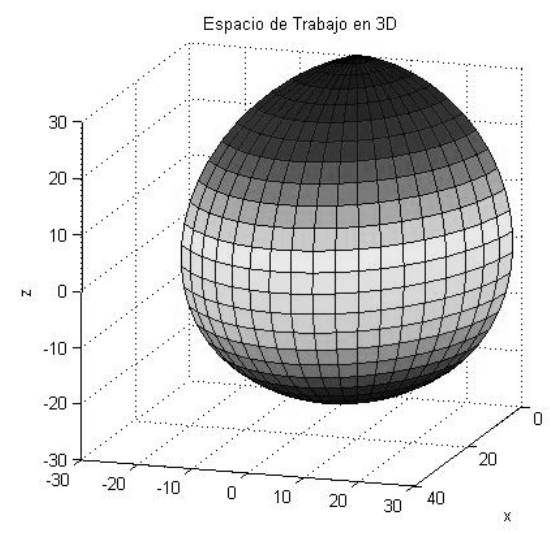

Figure 3. Workspace of the parallel mechanism.

\subsection{Kinematic modeling of an artificial muscle}

Figure 4 shows a linear electric actuator diagram. This kind of actuators has the capacity of emulating the movement of a biological muscle. This device could be considered an artificial muscle with characteristics like those of human muscles for elbow prosthesis. 

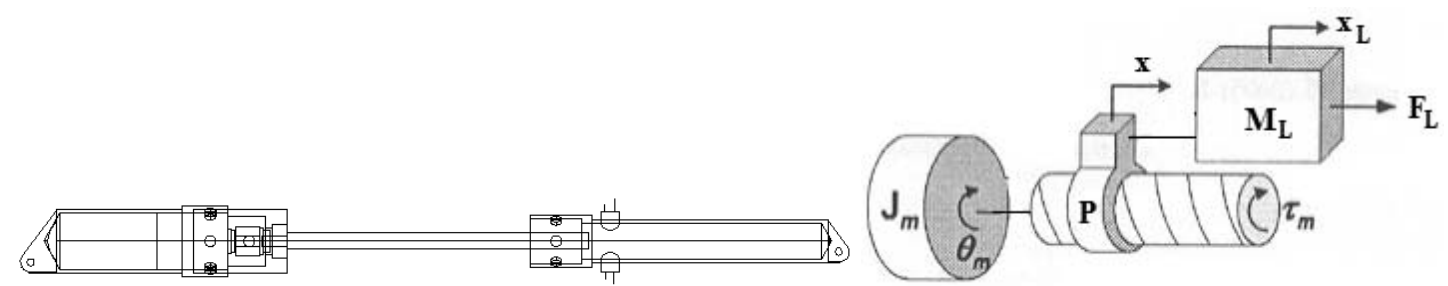

Figure 4. a) Scheme of linear electric actuator mechanism b) Free body diagram for the linear electrical actuator.

Figure 5 shows the relationship between the angular advance caused by the motor and the linear advance after the ball screw; in this case, $\beta$ represents the angle of the ball-screw lead; I represents the step of the lead and $x(t)$ the linear advance [30][31]. In this way,

$$
x(t)=\frac{l}{2 \pi} \theta_{m}(t)
$$

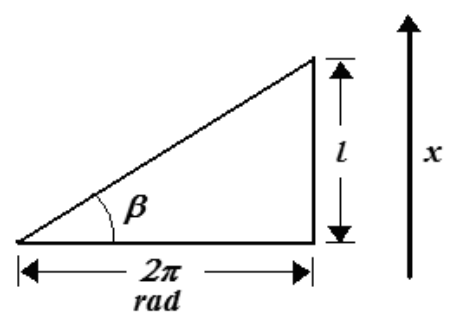

Figure 5. Workspace of the parallel mechanism.

Where $\theta_{m}(t)$ is given in radians and represents the angular advance generated by the motor. From (2) we have:

$$
\theta_{m}(t)=\frac{2 \pi}{l} x(t)
$$

With (3), the relation between angle position and linear position is found and lets us evaluate the movements required for a linear electric actuator in a prosthetic elbow.

\subsection{Spatial kinematic model}

In Fig. 6, the parallel mechanism of 3DOF to emulate the model by geometric methods is shown. For this mechanism. Let us consider the homogeneous transformation matrix given by (1), with the orthogonal-considerations. Considering that the positions of the linear actuators regarding the platform and the foundation are known in advanced by their coordinates.

The evaluation of $q_{i}$, which is the vector from the origin to each point placed at the end of the actuator on the platform, is determined by (4), which generates three equations (q1, q2, q3) related with the base-points to the platformpoints.

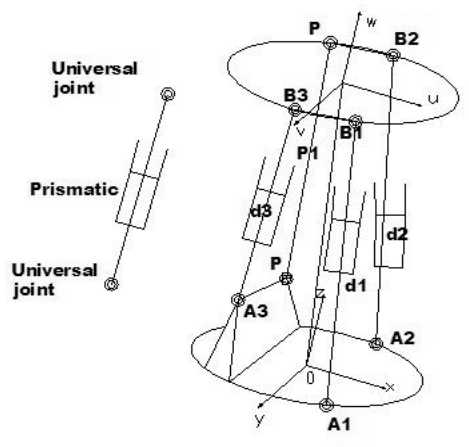

Figure 6. Simplified parallel mechanism. 


$$
q_{i}=p+{ }^{A} R_{B}{ }^{B} b_{i}
$$

The distance of each linear actuator is obtained through (5), to derive the spatial kinematic model of the parallel mechanism to be used in the prosthetic elbow with 3 DOF. Finally, the inverse kinematic model for this parallel mechanism for prosthesis applications is (6):

$$
\begin{aligned}
& d_{i}^{2}=\left[q_{i}-a_{i}\right]^{T}\left[q_{i}-a_{i}\right] \\
& \left\|d_{i}\right\|=\sqrt{\left[q_{i}-a_{i}\right]^{T}\left[q_{i}-a_{i}\right]}
\end{aligned}
$$

With (6), the flexion-extension, pronationsupination and humeral rotation angles are found and let us evaluate the movements required for a prosthetic elbow, which should perform the movements of a biological one.

\section{Simulation}

From (1) to (6), implemented in MatLab, a simulator and graphics of the behavior are obtained, which facilitates the study on inverse kinematics. In this manner, one can simulate the evolution of the DOFs from and to the desired position of the mechanism.

The simulator displays kinematic behaviors of the parallel mechanism in 3 dimensions to view and make the movements required for the prosthetic elbow (see Fig. 9). It also assesses the behavior of the actuators and their extensions or contractions as an entire body, to verify that the structure is hold in a single block. The simulator allows us to get insight on aspects for a redesign, which is by changing geometric parameters, angles, lengths and others to explore alternatives and mechanism of the elbow.

\subsection{Simulations results}

\subsubsection{Linear electric actuator}

Fig. 7 shows the linear electric actuator in extending and contracting modes. Figure 8 shows the behaviors of the linear electric actuators in the linear electric actuator for a parallel mechanical elbow, in this case the displacement is linear both of angular and linear position.

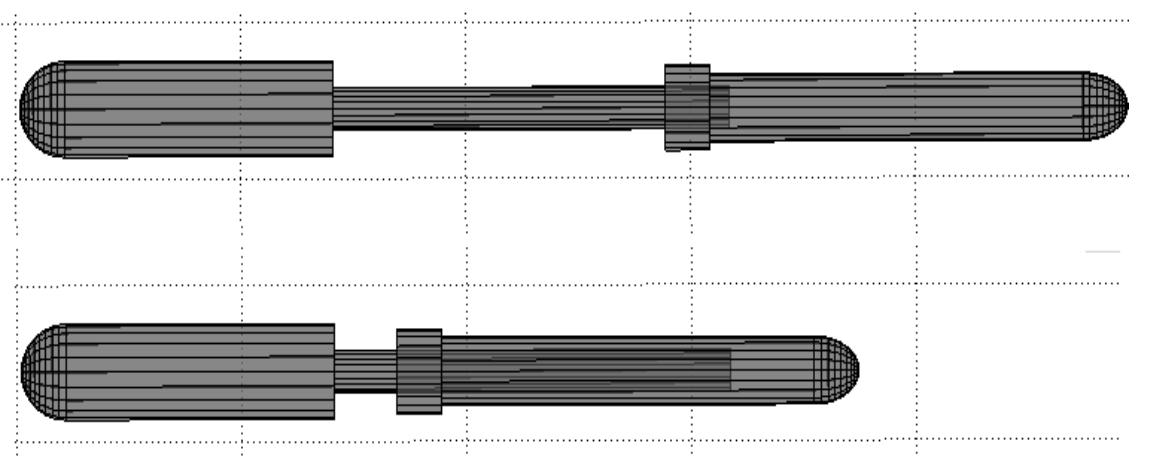

a)

b)

Figure 7. a) Linear actuator extended b) linear actuator contracted. 


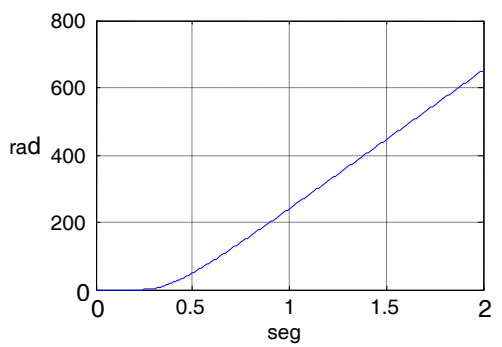

a)

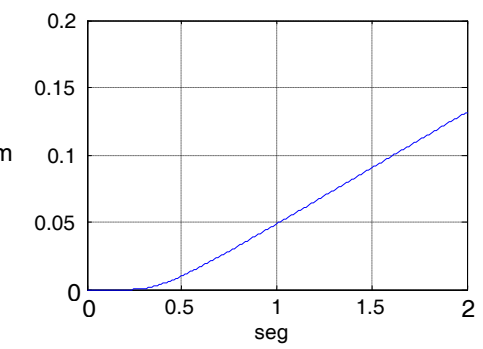

b)

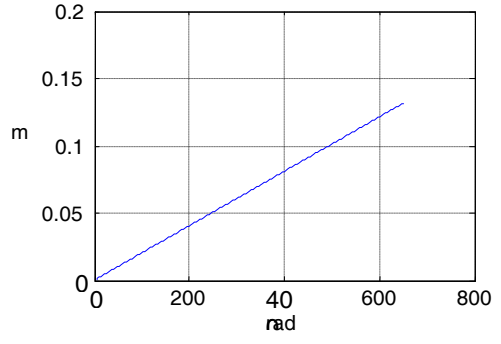

c)

Figure 8. a) Angular position b) Linear Position c) Angular position vs. linear position.

In Fig. 9 to Fig. 10, the behaviors of the linear electric actuators in the parallel mechanical elbow are shown. For flexion-extension, only two actuators ( 1 and 2 ) perform movement. Similarly, for the humeral rotation, only actuators 2 and 3 perform movement.
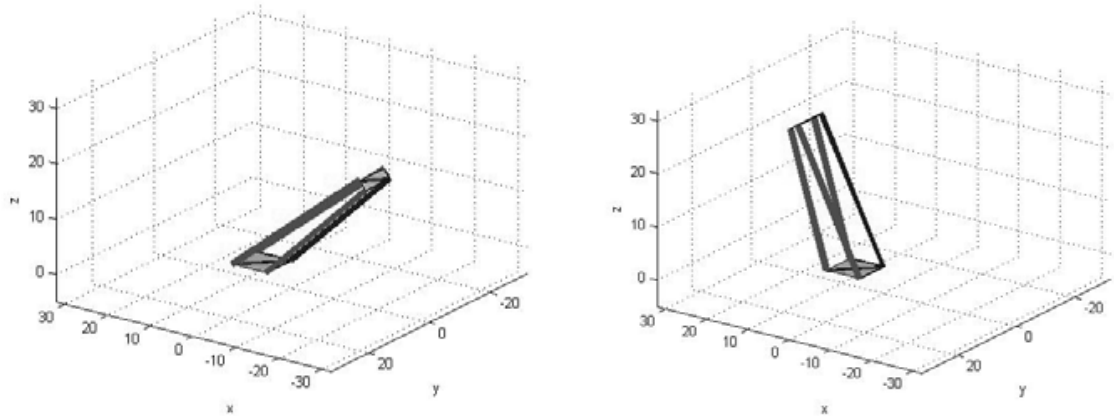

Figure 9. Simulation of the parallel mechanism in flexion-extension movement.
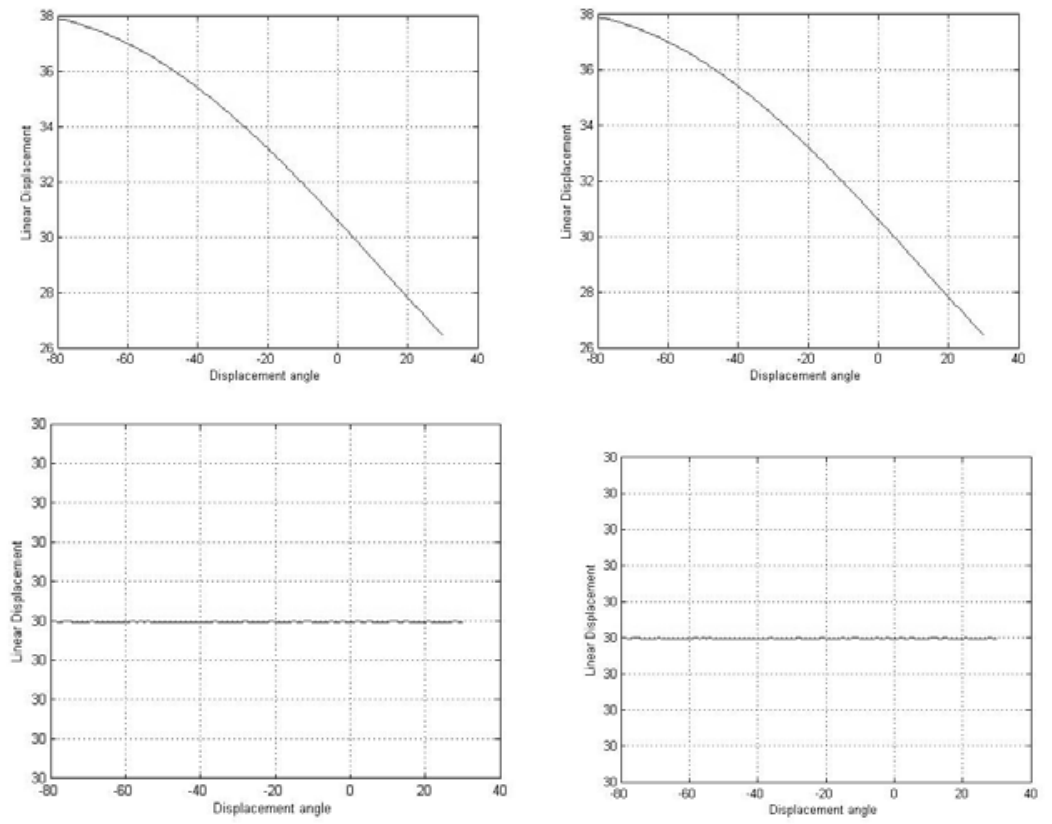

Figure 10. Behavior of the linear electric actuator 1,2,3,4 in flexion-extension movement. 
Finally, the movement of pronation-supination is shown in Fig. 11 to Fig. 12; in this case, the linear actuator 3 performs movement in order to reach the desired movement. One can see that actuators 1 and 3 perform the same movement behaviors.
In humeral rotation, similar results are obtained and actuators 2 and 3 develop movement while actuator 3 does not. Graphics in the previous sections show that is possible for this mechanism to develop the same movements like a biological arm as flexion-extension, pronation-supination and humeral rotation. Thanks to this, a patient can use this mechanism and perform many tasks in his life.

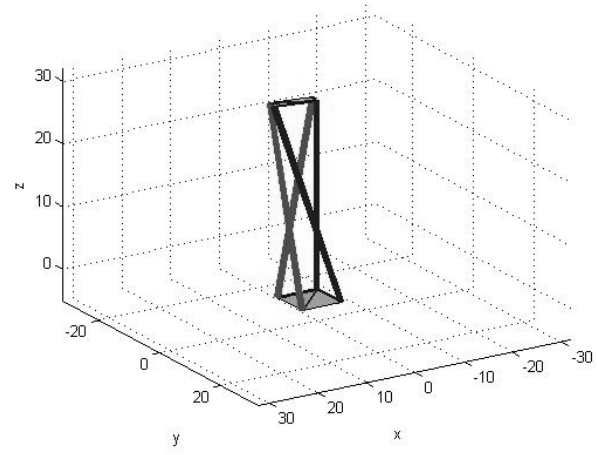

Figure 11. Simulation for a parallel mechanism in pronation-supination movement.
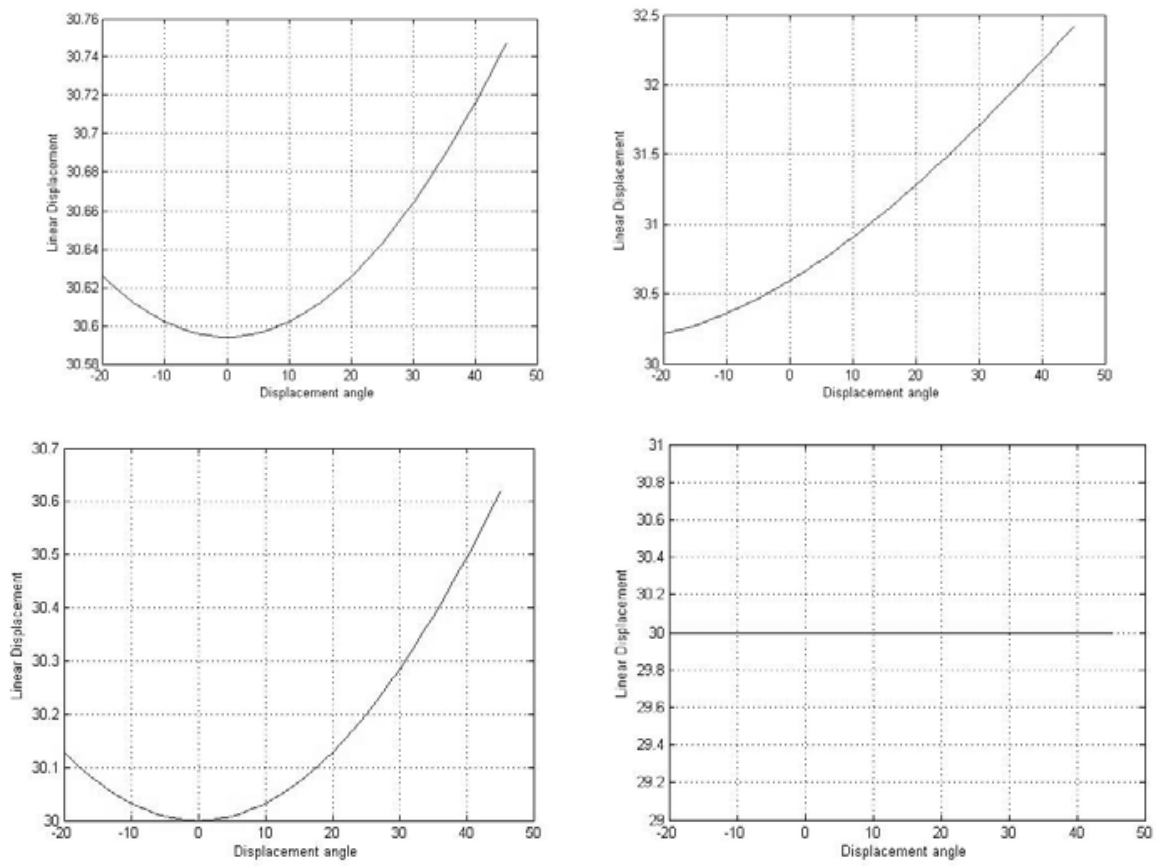

Figure 12. Behavior of the linear electric actuator 1,2,3,4 in pronation-supination movement. 


\section{Conclusion}

It was shown that the kinematic model of a parallel robot does not have the same characteristics as for a series robot. Furthermore, the kinematic analysis for a parallel mechanic elbow has been introduced. Some design aspects and the most relevant details of their physical structure, the mechanics and kinematics, have been described. As main features, it includes: anthropomorphic, 3 DOF as a mechanism; mechanically self-contained, to be tailored to the patient; modularity of hardware and software to facilitate the addition, modification, expansion or replacement of parts.

The characteristics of the prosthetic functions such as large number of DOFs, control and easy of movement, light, and anthropomorphic high performance characteristics, depend directly from the actuators and mechanisms that are used in prosthetics.

The parallel prototype has been inspired by the human biological elbow operation and it was intended to be a medium to seek for functional restoration in patients with transhumeral amputation.

Finally, a simulator to view graphics on the scene in a realistic, simple and visual sense has been developed, and it shows its usefulness for the analysis of a three-dimensional kinematic mechanism, which is a test-bed for the elbow designed as a parallel mechanism.

\section{References}

[1] Hugh Herr, G. Paul Whiteley, Dudley Childress, Cyborg Technology. Northwestern University Technical Report. 2000

[2] Thomas Andrew. Prosthetics principles. Atlas of Limb prosthetics. 1992
[3]] Harold Sears. Advances in arm prosthetics. Motion Control Inc. 1999.

[4] Gow, D. J.; Douglas, W.; Geggie, C.; Monteith, E.; Stewart, D. "The development of the Edinburgh modular arm system". Proceedings Of The Institution Of Mechanical Engineers Part H-Journal Of Engineering In Medicine 291-298 2001

[5] Todd Kuiken. Boston Digital Arm. Liberating technologies. 2006.

[6] Sabater [J.M. Azorin J.M. Castillo M. Ñeco, R Jiménez L.M. Diseño y control de un sistema de $2 \mathrm{GDL}$ formado por músculos neumáticos en oposición. XXV Jornadas de automática 2004.

[7] D.J. Magermans E.K.J., Chadwick, H.E.J. Veeger, F.C.T van der Helm. Requirements for upper extremity motions during activities of daily living. Clinical Biomechanics No. 2 Elsevier. September 2003

[8] Rodríguez C.F. Quintero Hugo, Aschner Helena. Movimiento del brazo humano: de los tres planos a las tres dimensiones. Revista de Ingeniería. Facultad de Ingeniería, Universidad de los Andes. Nov. de 2005.

[9] B. F. Morrey, E.Y. Chao. Passive motion of the elbow joint. Journal of Bone joint surgery. 1976.

[10] G. Paraskevas, Papadopoulos A., Papaziogas B., Sponidou S., Argiriadou H., Gigis J. Study of the carry angle of the human elbow joint in full extension: a morphometric analysis. Springer Verlag 2003.

[11] Escudero A.Z., Alvarez J., Leija L. "Development and characterization of electromechanical muscles for driving trans-humeral myoelectric prostheses". Prosthetics and Orthotics International, Vol 26, Pp 226234. 2002.

[12] Escudero A.Z., Alvarez J., Leija L. Inverse Kinematics for a parallel myoelectric elbow. 23th Annual Int. Conference of the IEEE Engineering in Medicine and Biology society, Oct. 2001. 
[13] Vanderlei O. Del Cura, Fransérgio L. Cunha, Manoel L. Aguiar, Alberto Cliquet Jr. Study of the different types of actuators and mechanism for upper limb prostheses. International Society for Artificial Organs. 2003.

[14] Klute Glenn et al. Artificial muscles: actuators for biorobotic systems. International Journal of Robotics Research. 2002.

[15] Vidyasagar M. and Spong M. "Robot Dynamics and Control" John Wiley \& Sons, 1989.

[16] Merlet, Jean Pierre. Parallel Robots. Kluwer Academic Publishers. 2006.

[17] Merlet J.P. Solving the forward kinematics of a Gough-type parallel manipulator with interval analysis. International Journal of Robotics Research. 2001.

[18] Chablat. D, et al. An interval analysis based study for the design and the comparison of 3 DOF parallel kinematic machines. International Journal of Robotics Research. 2001.

[19] Quin Jin, Ting-Li Yang Theory for topology synthesis of parallel manipulators and its application to three dimension-translation parallel manipulators. Journal of mechanical Design, ASME, Vol. 126. 2004.

[20] Lung-Wen Tsai, Gregory C. Walsh and Richard E. Stamper. Kinematics of a novel three DOF Translational platform. IEEE INRA. April 1996.

[21] A. Wolf, M. Shoham, Investigation of parallel manipulators using linear complex approximation. Transaction of ASME, Sept. 2003.

[22] J.M. Rico J. Gallardo, J. Duffi. Screw theory and higher order kinematics analysis of open serial and closed chains. Mechanism and machine theory. Elsevier. 1997.

[23] D. Zhang, C.M. Gosselin. Kinetostatic modeling of parallel mechanism with a passive constraining leg and revolute actuators. Mechanism and machine theory. Elsevier. 2001.

[24] J. J. Cervantes S. Moreno Baez Miguel., Rico Martínez J.M., González Galván E.J. A novel geometrical derivation of the Lie Product. Mechanism and machine theory. Elsevier. 2004.

[25] Bonev I.A. Geometric analysis of parallel mechanisms Ph.D. Laval University. Québec Q.C. Canada Nov. 2002.

[26] Gosselin C.M. "Parallel computation algorithms for the kinematics and dynamics of parallel manipulators" Procc. of IEEE Int. Conference Robotics and automation 1993

[27] Gosselin C. M. y Carretero J. A. "Kinematic analysis of a three-DOF parallel mechanism for telescope application". ASME. Design Engineering Technical Conference and Computers in Engineering Conference. USA. 1997.

[28] Ilian A. Bonev, Jeha Ryu. A new method for solving the direct kinematics of general 6-6 Stewart Platforms using three linear extra sensors. Mechanism and machine theory. Elsevier. 2004.

[29] Rafael Mendoza-Vázquez, A.Z. Escudero Uribe, R. Fernández Mulia. Simplified Analytical Dynamic Model for a Parallel Prosthetic Elbow. XXIX IEEE EMBS 2007 Lyon France.

[30] Cuachiltl, José Álvaro. Tesis. Mecanismos para control y modelo de la máquina generadora de superficies asféricas. Instituto Nacional de Astrofísica, Óptica y Electrónica. México; 2000. pp 99

[31] Min-Seok Kim y Sung-Chong Chung. 2005. "A systematic approach to design high-performance feed drive system." International Journal of Machine Tools \& Manufacture. pp 1421-1435. 


\section{Authors Biography}

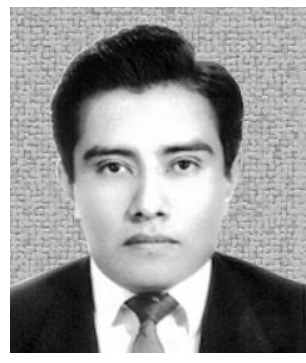

\section{Jose Rafael MENDOZA-VAZQUEZ}

He received the B.Sc. degree from the Instituto Tecnológico de Puebla (ITP), Mexico, in 1993, the M.Sc. degree from the Instituto Nacional de Astrofisica, Óptica y Electrónica (INAOE), Mexico, in 2003. Currently, he is pursuing his Ph.D. degree in the Instituto Nacional de Astrofisica, Óptica y Electrónica (INAOE). He has authored or coauthored more than 10 papers in national and international conferences. His research interests include modeling and simulation of electromechanical systems, robotics systems, parallel-serial mechanisms and visual control.

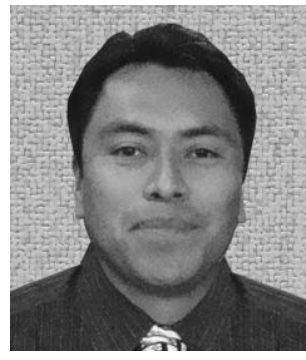

\section{Esteban TLELO-CUAUTLE}

He received the B.Sc. degree from the Instituto Tecnológico de Puebla (ITP), Mexico, in 1993, and the M.Sc. and Ph.D. degrees from the Instituto Nacional de Astrofisica, Optica y Electronica (INAOE), Mexico, in 1995 and 2000, respectively. In 1995 he joined the ITP and since 2001 he has been a full researcher at INAOE. He has authored or coauthored more than 120 papers on scientific journals, book chapters and conference proceedings. He is a senior member of the IEEE and a member of IEICE. He is a member of the editorial board of the Journal of Applied Sciences, and serves as reviewer of 16 journals, among them: IEEE Trans on Computer-Aided Design; IEEE Trans on Circuits and Systems; IET Circuits, Devices \& Systems; Int Journal of Electronics; Rev Mexicana de Física; IET Electronics Letters; Circuits, Systems and Signal Processing; IEEE Latin-America Transactions; Analog Integrated Circuits and Signal Processing and SCI Journal. He has been a member of the Program Committee in MDES 2009; IEEE ICECS 2009; WCECS 2007-2009; IEEE and ACM CSTST-2008; and IASTED Circuits, Signals and Systems 2003-2005. He has been reviewer in 15 international conferences, among them: IEEE CERMA, IEEE APCCAS, IEEE ISCAS, IEEE ECCTD and IEEE ANDESCON. His research interests include modeling and simulation of linear and nonlinear circuits and systems, symbolic analysis, circuit synthesis, and analog/RF and mixed-signal CAD tools. 


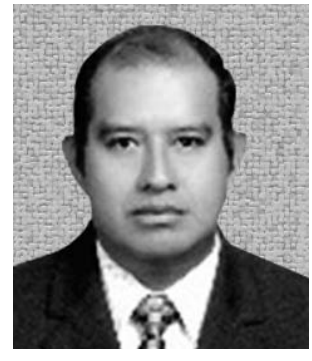

Jose L. VAZQUEZ-GONZALEZ

He has been a full-time professor at Universidad de las Américas in Puebla, Mexico since 1998. He received his Ph.D. degree in electronics from the Instituto Nacional de Astrofisica, Óptica and Electrónica (INAOE) in 1999. Dr. Vazquez has directed more than 50 undergraduate level theses and 10 graduate level theses; also, he has been a reviewer of 20 undergraduate level theses and 5 graduate level theses. Dr. Vazquez has coordinated three research projects supported by the National Institute for Research and Postgraduate (INIP) of the UDLA-P. His areas of interest are statistical design of analog integrated circuits as well as instrumentation and control. He has published more than 20 papers in national and international conferences. His research interests are statistical methods, alternatives of control, fuzzy control and the neuronal control in application of circuits integrated (VLSI).

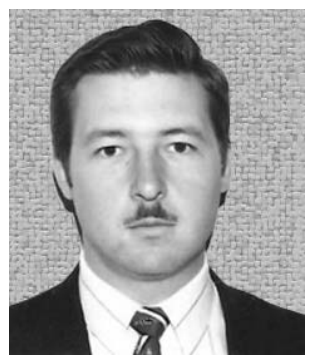

\section{Apolo Z. ESCUDERO-URIBE}

He was born in 1971 in Mexico. He graduated from Instituto Tecnológico de Puebla in Electronic Engineering in 1992 and received his Ph. D. degree from Centro de Investigación y de Estudios Avanzados del Instituto Politécnico Nacional de México in 2002. His doctoral thesis was awarded by the Mexican Academy of Sciences as the best Ph. D. work in Mexico in the year 2002. He is currently an electronic engineering researcher professor at Instituto Tecnológico de Monterrey. His research interests are biomedical instrumentation, prosthetics and myoelectric control. 